\title{
Family history of type 2 diabetes: A population-based screening tool for prevention?
}

\author{
Susan Hariri, PhD ${ }^{1,2}$, Paula W. Yoon, $S c D^{2}$, Nadeem Qureshi, $M B B S^{2}$, Rodolfo Valdez, $P h D^{3}$,
} Maren T. Scheuner, $M D^{2,4}$, and Muin J. Khoury, $M D, P h D^{2}$

\begin{abstract}
Purpose: To evaluate the use of self-reported family medical history as a potential screening tool to identify people at-risk for diabetes. Methods: The HealthStyles 2004 mail survey comprises 4345 US adults who completed a questionnaire to ascertain personal and family history of diabetes, perceived risk of diabetes, and practice of risk-reducing behaviors. Using number and type of affected relatives, respondents were ranked into three familial risk levels. Adjusted odds ratios (AORs) were obtained to evaluate associations between familial risk and prevalent diabetes, perceived risk of disease, and risk-reducing behaviors. Validity of family history as a screening tool was examined by calculating sensitivity, specificity, and positive and negative predictive values. Results: Compared to those of average risk, people with moderate and high familial risk of diabetes were more likely to report a diagnosis of diabetes (AOR: 3.6, 95\% Cl: 2.8, 4.7; OR: 7.6, 95\% Cl: 5.9, 9.8, respectively), a higher perceived risk of diabetes (AOR: 4.6, 95\% Cl: 3.7, 5.7; OR: 8.5, 95\% Cl: 6.6, 17.7, respectively), and making lifestyle changes to prevent diabetes (AOR: 2.2, 95\% Cl: 1.8, 2.7; OR: 4.5, 95\% Cl: 3.6, 5.6, respectively). A positive familial risk of diabetes identified $73 \%$ of all respondents with diabetes and correctly predicted prevalent diabetes in $21.5 \%$ of respondents. Conclusion: Family history of diabetes is not only a risk factor for the disease but is also positively associated with risk awareness and risk-reducing behaviors. It may provide a useful screening tool for detection and prevention of diabetes. Genet Med 2006:8(2):102-108.
\end{abstract}

Key Words: family history, type 2 diabetes, screening, risk factor, prevention

Type 2 diabetes accounts for $90 \%-95 \%$ of all cases of diabetes $^{1}$ and is a classic example of a multifactorial disease involving the complex interplay of modifiable and nonmodifiable risk factors, including family history, obesity, ethnicity, and age. ${ }^{1-5}$ In recent years, the prevalence of type 2 diabetes (T2DM) has been steadily increasing in the US, especially among adolescents and African Americans. ${ }^{6-13}$

Given that the onset of and complications from T2DM can be delayed or prevented, ${ }^{14-18}$ understanding the separate and joint contribution of genetics and environment in the development of T2DM remains an important challenge toward its prevention and control. Family history of a disease reflects shared environmental and behavioral risk factors and their interactions with genes as shown by the strong familial aggregation of many complex disorders. ${ }^{19-23}$ In fact, family history is an independent risk factor for most common chronic diseases

\footnotetext{
From the ${ }^{1}$ Epidemic Intelligence Service Officer, Office of Workforce and Career Development, Centers for Disease Control and Prevention, Atlanta, Georgia; ${ }^{2}$ Office of Genomics and Disease Prevention, Centers for Disease Control and Prevention, Atlanta, Georgia; ${ }^{3}$ Division of Diabetes Translation, National Center for Chronic Disease Prevention and Health Promotion, Centers for Disease Control and Prevention, Atlanta, Goergia; ${ }^{4}$ Department of Health Services, UCLA School of Public Health, California.

Dr. Susan Hariri, 4770 Buford Highway, Mailstop K-89, Atlanta, Georgia 30341.

Received for publication August 5, 2005.

Accepted for publication October 22, 2005.
}

DOI: 10.1097/01.gim.0000200949.52795.df including cardiovascular disease, cancer, and T2DM..$^{2,3,6,19-24}$ Recent surveys indicate that the majority of US adults are aware of and can report T2DM among first-degree relatives ( $88 \%-95 \%$, depending on type of relative) and, to a lesser extent, second-degree relatives (70\%-77\%, depending on type of relative) ${ }^{25}$ Given such family history knowledge and the public health importance of this chronic condition, family history may provide a useful screening tool for detection and prevention of T2DM and its sequelae.

This study was designed to evaluate the use of self-reported family history of T2DM as a potential screening tool to identify people at increased risk of T2DM and the proportion of persons with undiagnosed T2DM. The specific aims were to assess: 1) family history of T2DM as an independent risk factor for T2DM; 2) possible modification of the association between familial risk and T2DM by other risk factors; and 3) relationship between family history of T2DM and perceived risk of the disease and the presence of risk-reducing behaviors.

\section{MATERIALS AND METHODS}

\section{Study design}

This cross-sectional study is based on the HealthStyles 2004, an annual mail survey of health-related attitudes and behaviors among the US adult population aged 18 and older. ${ }^{26} \mathrm{Health}$ Styles is a subset of a two-part consumer survey designed and 
conducted by Synovate, Inc., a marketing firm that annually recruits approximately 600,000 potential respondents.

HealthStyles is used for health communications planning by organizations, including the Centers for Disease Control and Prevention, who influence design and administration of the questionnaire. The data from the survey are post-stratified and weighted so that the sample distribution by age, race, sex, household size, and household income matches the U.S. general population as reported by the U.S. census.

In 2004, HealthStyles surveys were sent to a random sample of 6175 US adults residing in households who participated in the consumer marketing component of the survey; 4345 agreed to participate, yielding a response rate of $70 \%$.

\section{Variable definitions}

The survey included a question about personal history of physician-diagnosed T2DM ("Have you ever been diagnosed by your doctor as having type 2 diabetes?"), as well as questions about current or recent (in the past year) medical conditions such as obesity (defined as "BMI $>30^{\prime \prime}$ ). Additionally, respondents were asked to identify all first-degree (mother, father, brothers and sisters) and second-degree (maternal and paternal aunts, uncles, and grandparents) biological relatives with T2DM. The survey also assessed whether respondents considered family history "very" or "somewhat" important for their own health, and whether they had ever actively collected health information from their relatives for the purposes of developing a family health history. Attitudes toward and perceived risk of T2DM were examined by the respondents' agreement or disagreement with statements such as "Diabetes is a serious disease," "I believe I am at risk for diabetes," and "I believe my family are at risk for diabetes" ranked on a Likert scale. Respondents' behaviors with respect to diabetes were ascertained through several questions related to risk-reducing behaviors such as obtaining regular testing and lifestyle changes such as diet and exercise to prevent diabetes. Although T2DM is likely to represent the majority of cases in respondents and their families, the term diabetes will be used throughout the manuscript to account for the possibility that some cases of type 1 diabetes may have been misreported. However, any such misreporting would be insignificant and unlikely to affect results of the analysis.

\section{Statistical analysis}

Using number and type of affected relatives, respondents were classified into average, moderate, or high familial risk according to the algorithm below, adapted from Scheuner et al. ${ }^{27}$ :

High: At least 1) two first-degree relatives with diabetes from same lineage; 2) one first- and two second-degree relatives with diabetes from same lineage; or 3 ) three second-degree relatives with diabetes from same lineage.

Moderate: Only 1) one first- and one second-degree relative with diabetes from same lineage; 2 ) one first-degree relative with diabetes; 3 ) mother and father with diabetes, or 4) two second-degree relatives from same lineage with diabetes.
Average: Only 1) one second-degree relative with diabetes from one or both sides of family; or no family history of diabetes.

Family history is often considered as a risk factor for diabetes without regard to the variable magnitude of risk based on different familial risk profiles. We used a three-tiered familial risk stratification to more accurately measure the effects of familial history on diabetes risk.

Demographic characteristics, diabetes risk factors, and potential confounders were evaluated individually; then unconditional logistic regression (overall and stratified by potential effect modifiers) was performed to obtain adjusted odds ratios (AOR) for the association between family history of diabetes and self-reported diabetes. Likewise, the association between increasing levels of familial risk and perceived risk of disease and risk-reducing behaviors was evaluated. Although all analyses were performed with and without the sampling weights developed for HealthStyles 2004, only unweighted results are presented as they did not differ from those obtained in the weighted analysis.

Finally, in addition to the above risk stratification, familial risk was dichotomized by combining the moderate and high risk categories, and sensitivity and specificity (ability of family history to correctly identify respondents with and without diabetes, respectively), and positive and negative predictive values (probability of an individual having or not having diabetes, respectively, given that he/she has a family history) were calculated. All measures were compared with the ability of self-reported obesity to detect the same risks.

\section{RESULTS}

Based on the familial risk stratification, 711 (16.4\%) respondents were classified into high-risk, 843 (19.4\%) into moderate-risk, and 2791 (64.2\%) into average-risk for diabetes. Of the 452 respondents with self-reported diabetes, 204 (45.1\%) were classified as high-risk, $125(27.7 \%)$ as moderate-risk, and $123(27.2 \%)$ as average-risk.

\section{Demographic characteristics}

Table 1 presents the distribution of the characteristics of the study population overall and within familial risk strata. The majority of respondents were 35 years or older $(82.1 \%)$, female $(56.7 \%)$, and white $(69.8 \%)$, with at least some college education $(67.1 \%)$ and annual incomes greater than $\$ 25,000$ (71.4\%). In addition, $16.8 \%$ of respondents reported being obese. Full details of the prevalence of diabetes by selected demographic characteristics, overall and within familial riskbased strata, are summarized in Table 2. There was a graded increase in diabetes prevalence with increasing family historybased risk: average (4.5\%), moderate (15.0\%), and high (29.1\%), even when stratified by other risk factors such as obesity and race. 
Table 1

Distribution of select respondent characteristics overall and classified by familial risk of diabetes, HealthStyles 2004

\begin{tabular}{|c|c|c|c|c|}
\hline & $\begin{array}{l}\text { Overall }(\mathrm{N}=4345) \\
\% \text { respondents }\end{array}$ & $\begin{array}{c}\text { Average risk }(\mathrm{N}=2791) \\
\% \text { respondents }\end{array}$ & $\begin{array}{c}\text { Moderate risk }(\mathrm{N}=843) \\
\% \text { respondents }\end{array}$ & $\begin{array}{l}\text { High risk }(\mathrm{N}=711) \\
\% \text { respondents }\end{array}$ \\
\hline \multicolumn{5}{|l|}{ Age, years } \\
\hline $18-34$ & 17.9 & 19.3 & 16.0 & 14.2 \\
\hline $35-54$ & 51.1 & 50.2 & 53.5 & 51.8 \\
\hline$\geq 55$ & 31.0 & 30.4 & 30.5 & 34.0 \\
\hline \multicolumn{5}{|l|}{ Sex } \\
\hline Male & 43.3 & 44.9 & 42.6 & 38.1 \\
\hline Female & 56.7 & 55.1 & 57.4 & 61.9 \\
\hline \multicolumn{5}{|l|}{ Race/ethnicity } \\
\hline White & 69.8 & 71.9 & 70.9 & 59.8 \\
\hline African American & 12.2 & 10.8 & 11.4 & 18.7 \\
\hline Latino & 11.6 & 10.3 & 11.5 & 16.5 \\
\hline Other & 6.5 & 7.0 & 6.2 & 5.1 \\
\hline \multicolumn{5}{|l|}{ Education } \\
\hline High school or less & 33.9 & 30.7 & 27.5 & 23.1 \\
\hline Some college & 36.8 & 34.7 & 35.8 & 35.4 \\
\hline College or more & 30.3 & 29.8 & 31.7 & 36.8 \\
\hline \multicolumn{5}{|l|}{ Income } \\
\hline$<\$ 25,000$ & 29.5 & 39.0 & 37.8 & 27.7 \\
\hline$\$ 25,000-59,999$ & 33.6 & 33.8 & 32.3 & 34.3 \\
\hline$>\$ 59,999$ & 36.9 & 27.2 & 29.9 & 38.0 \\
\hline \multicolumn{5}{|l|}{ Self-reported obesity } \\
\hline Yes & 16.8 & 13.6 & 19.1 & 26.7 \\
\hline No & 83.2 & 86.4 & 80.9 & 73.3 \\
\hline \multicolumn{5}{|l|}{ Current smoker } \\
\hline Yes & 22.6 & 22.2 & 22.8 & 24.1 \\
\hline No & 77.4 & 77.8 & 77.2 & 75.9 \\
\hline \multicolumn{5}{|c|}{ Met recommended exercise guidelines } \\
\hline Yes & 38.1 & 38.0 & 36.7 & 40.0 \\
\hline No & 61.9 & 62.0 & 63.3 & 60.0 \\
\hline
\end{tabular}

\section{Family history and other risk factors for diabetes}

Overall, people with moderate and high familial risk of diabetes were more likely to report a diagnosis of diabetes (AOR: 3.6, 95\% CI: 2.8, 4.7; OR: 7.6, 95\% CI: 5.9, 9.8, respectively) then those with average risk.

Among risk factors examined, advanced age, non-white race, low income and education, and self-reported obesity were statistically significantly associated with diabetes risk, and were evaluated as potential modifiers (along with gender) for the association between familial risk and diabetes. While the strength of this association increased with increasing familial risk across all categories of risk factors examined, the effect of family history appeared to diminish among females, the elderly, and the obese (Table 3).

\section{Attitudes and behaviors}

Overall, $96 \%$ of respondents ranked knowledge of family history of disease as either "very" or "somewhat" important to their personal health; this proportion did not vary when stratified by family history-based risk strata. Likewise, there was over $95 \%$ agreement among respondents in all familial risk categories that diabetes is a serious disease. However, among respondents without diabetes, perceived risk of diabetes increased significantly with increasing family history-based risk. While only $14 \%$ of respondents in the average risk group believed themselves to be at risk for diabetes, more (36\%) respondents in the moderate risk group, and even more (51\%) in the high risk group considered themselves at risk. Likewise, $18 \%$ of repondents in the average risk group felt their family 
Table 2

Prevalence of diabetes in total population and by selected demographics characteristics overall and within familial risk strata, HealthStyles 2004

\begin{tabular}{|c|c|c|c|c|}
\hline \multirow[b]{2}{*}{ Prevalence of type 2 diabetes } & \multicolumn{4}{|c|}{ Prevalence of type 2 diabetes } \\
\hline & Overall $(\mathrm{N}=452)$ & Average risk $(\mathrm{N}=123)$ & Moderate risk $(\mathrm{N}=125)$ & High risk $(\mathrm{N}=204)$ \\
\hline Total & 10.6 & 4.5 & 15.0 & 29.1 \\
\hline \multicolumn{5}{|l|}{ Select characteristics } \\
\hline \multicolumn{5}{|l|}{ Age } \\
\hline $18-34$ & 2.9 & 0.6 & 4.4 & 12.9 \\
\hline $35-54$ & 7.9 & 2.2 & 13.1 & 22.6 \\
\hline$\geq 55$ & 19.5 & 10.5 & 23.3 & 44.6 \\
\hline \multicolumn{5}{|l|}{ Sex } \\
\hline Female & 10.1 & 4.4 & 14.5 & 24.5 \\
\hline Male & 11.2 & 4.5 & 15.3 & 35.4 \\
\hline \multicolumn{5}{|l|}{ Race } \\
\hline White & 9.8 & 4.5 & 14.2 & 27.3 \\
\hline Black & 13.4 & 4.7 & 13.5 & 31.6 \\
\hline Hispanic & 12.9 & 4.2 & 16.5 & 29.9 \\
\hline \multicolumn{5}{|l|}{ Education } \\
\hline College + & 7.9 & 3.6 & 12.9 & 22.6 \\
\hline Some college & 10.1 & 4.9 & 13.2 & 25.4 \\
\hline HS or less & 13.3 & 4.5 & 18.0 & 35.1 \\
\hline \multicolumn{5}{|l|}{ Income } \\
\hline$>\$ 59,999$ & 7.0 & 3.1 & 11.9 & 19.8 \\
\hline$\$ 25,000-59,999$ & 9.2 & 3.8 & 12.5 & 25.4 \\
\hline$<\$ 25,000$ & 16.8 & 7.0 & 21.0 & 38.1 \\
\hline \multicolumn{5}{|l|}{ Obesity } \\
\hline $\mathrm{BMI}<30$ & 7.7 & 3.1 & 11.0 & 23.2 \\
\hline $\mathrm{BMI}>30$ & 25.0 & 12.6 & 31.1 & 43.7 \\
\hline \multicolumn{5}{|l|}{ Current smoker } \\
\hline Yes & 10.3 & 4.1 & 16.1 & 25.3 \\
\hline No & 10.7 & 4.5 & 14.5 & 29.7 \\
\hline \multicolumn{5}{|l|}{ Met exercise guidelines } \\
\hline Yes & 7.3 & 2.6 & 9.8 & 21.8 \\
\hline No & 12.1 & 5.4 & 17.8 & 31.8 \\
\hline
\end{tabular}

members were at risk for diabetes compared to $44 \%$ in the moderate risk group and $62 \%$ in the high risk group. The associations between perceived risks and familial risk are presented in Table 4.

Association between familial risk and behaviors leading to risk reduction or an awareness of risk followed a similar trend as with risk perception. Respondents without diabetes in high familial risk categories were most likely to engage in behaviors such as collecting information from relatives for the purpose of developing a family history (43\%); making lifestyle changes to prevent diabetes (49\%); getting tested for diabetes in past two years (69\%); and talking with their family about diabetes
(73\%); followed by those with moderate familial risk (34\%, $32 \%, 57 \%$, and $54 \%$, respectively), with the average risk group reporting fewest such behaviors $(28 \%, 18 \%, 47 \%$, and $28 \%$, respectively). The association between familial risk and riskreducing behavior among moderate- and high-risk groups compared to the average-risk group was statistically significant for all behaviors and increased with increasing familial risk (Table 4).

\section{Assessment of familial risk as a screening tool}

The ability of familial risk to accurately and reliably identify self-reported diabetes, and the probability that a respondent 


\section{Hariri et al.}

Table 3

Association between familial risk and diabetes, overall and stratified by risk factors

\begin{tabular}{|c|c|c|c|}
\hline & $\begin{array}{r}\text { Average } \\
\text { AOR }^{a}\end{array}$ & $\begin{array}{c}\text { Moderate AOR } \\
\quad(95 \% \mathrm{CI})\end{array}$ & $\begin{array}{c}\text { HighAOR } \\
(95 \% \mathrm{CI})\end{array}$ \\
\hline Overall & 1.0 & $3.6(2.8,4.7)$ & $7.6(5.9,9.8)$ \\
\hline \multicolumn{4}{|l|}{ Race/ethnicity } \\
\hline White & 1.0 & $3.7(2.6,5.2)$ & $7.2(5.2,10.2)$ \\
\hline African American & 1.0 & $2.6(1.1,6.1)$ & $9.1(4.5,18.6)$ \\
\hline Latino & 1.0 & $4.1(1.7,9.8)$ & $9.7(4.4,21.4)$ \\
\hline \multicolumn{4}{|l|}{ Age, years } \\
\hline $18-34$ & 1.0 & $7.8(1.4,44.0)$ & $35.8(7.6,168.5)$ \\
\hline $35-54$ & 1.0 & $7.0(4.3,11.2)$ & $10.4(6.5,16.5)$ \\
\hline$\geq 55$ & 1.0 & $2.3(1.5,3.4)$ & $6.2(4.3,8.8)$ \\
\hline \multicolumn{4}{|l|}{ Sex } \\
\hline Male & 1.0 & $4.1(2.6,6.4)$ & $11.8(7.7,17.8)$ \\
\hline Female & 1.0 & $3.5(2.4,5.0)$ & $6.2(4.4,8.8)$ \\
\hline \multicolumn{4}{|l|}{ Self-reported obesity } \\
\hline Yes & 1.0 & $3.5(2.2,5.7)$ & $5.7(3.6,9.0)$ \\
\hline No & 1.0 & $3.8(2.7,5.5)$ & $9.5(6.8,13.3)$ \\
\hline
\end{tabular}

${ }^{a}$ Each model adjusted for all other demographic characteristics.

has undiagnosed diabetes based on familial risk are presented in Table 5. As indicated, a positive (moderate or high) familial risk of diabetes identified $73 \%$ of all respondents with diabetes. In contrast, only $40 \%$ of respondents with type 2 diabetes were identified by self-reported obesity, while the presence of both obesity and a positive family history of diabetes detected $29 \%$, indicating that family history is a better indicator of diabetes among this population than obesity. Moreover, the value of a positive familial risk of disease to predict diabetes in survey respondents was similar to that of the predictive value of obesity which is considered to be one of the most important determinants of diabetes ( $21.5 \%$ vs. $25.0 \%$, respectively). Predictably, the combination of the two risk factors increased disease prediction to almost $40 \%$ (Table 5).

\section{DISCUSSION}

The findings herein quantitatively demonstrate the ability of family history as a screening tool for detecting self-reported diabetes, suggesting the potential benefit of collection and use of family history information to identify at-risk and undiagnosed persons with diabetes. Specifically, the results show that a positive family history is a sensitive indicator of the presence of diabetes with much higher sensitivity than obesity, a well established risk factor. It also helps in the estimation of the probability of having the disease almost as accurately as selfreported obesity. Although comparable, the positive predictive values for both increased familial risk as well as obesity are low, potentially resulting in undue anxiety and financial burden in a high proportion of individuals that may unnecessarily receive further testing. However, use of family history in combination with obesity almost doubles the positive predictive value of each risk factor alone, representing a substantial reduction in false positive rates for screening. Given the consequences of undiagnosed diabetes to society and to individuals and the absence of more accurate screening tools, family history, in conjunction with obesity, provides a readily available, inexpensive screening tool to identify at-risk groups, as well as persons with undiagnosed diabetes, for evaluation, detection, and risk reducing interventions.

These findings also support previous studies demonstrating that family history is a strong and independent risk factor for diabetes. ${ }^{2,3,5,6,19}$ However, familial risk must be evaluated in the context of other known or suspected risk factors. These findings indicate differences in the effect of familial risk on other risk factors, suggesting that a high familial risk may increase diabetes risk in males, the young, and the lean. Finally, this analysis illustrates that increasing familial risk is associated with increases in risk-reducing behaviors, but more important, it shows that over half of those at moderate and high familial risk of diabetes fail to engage in risk reducing behaviors, highlighting the urgent need to improve current prevention programs, especially among those at increased risk for the disease.

This study has some important limitations. First, the familial risk stratification used in this analysis is based on best available clinical knowledge of diabetes inheritance and requires further population-level validation. Second, the cross-sectional design of the survey prohibits establishment of any temporal associations. This is of particular concern since persons with diagnosed diabetes may be more aware of diabetes in their family than those without diabetes, thus biasing the sensitivity analysis. Another potential concern is the validity of self-reported data. For example, obesity is likely to have been underreported leading to underestimation of its true prevalence in the study population. ${ }^{28}$ Also, persons with undiagnosed diabetes may be less aware of their family history, further biasing results. Finally, HealthStyles participants are a convenience sample and may not be representative of the general population. However, a study using data from the Behavioral Risk Factor Surveillance System showed that demographic characteristics and diabetes prevalence among the HealthStyles population were similar to that of the U.S. population. ${ }^{26}$ Nonetheless, the results of this study should be reproduced in larger, population-based studies that utilize relevant clinical measurements to allow for more accurate classification of diabetes.

Despite noted limitations, this analysis provides a unique example of how collecting comprehensive multi-generational family history information can be used to classify individuals according to increasing levels of disease risk based on the number and type of affected relatives. As such, this survey can be used as a model for types of family history questions that can be added to population-based surveys to identify individuals with undiagnosed diabetes as well as those at increased risk of the disease. From a more clinical perspective, because family history in part represents unmeasured genetic determinants of the 
Table 4

Effect of family history-based risk of type 2 diabetes on perceived risk of diabetes and behaviors to reduce risk or increase risk awareness among respondents without diabetes

\begin{tabular}{|c|c|c|c|}
\hline & $\begin{array}{l}\text { Average }(\mathrm{n}=2606) \\
\operatorname{AOR}^{a}(95 \% \mathrm{CI})\end{array}$ & $\begin{array}{l}\text { Moderate }(\mathrm{n}=706) \\
\text { AOR }(95 \% \mathrm{CI})\end{array}$ & $\begin{array}{l}\text { High }(\mathrm{n}=497) \\
\text { AOR }(95 \% \mathrm{CI})\end{array}$ \\
\hline \multicolumn{4}{|l|}{ Perceived risk of diabetes } \\
\hline Believed self at risk for diabetes & 1.0 & $4.6(3.7,5.7)$ & $8.5(6.6,17.7)$ \\
\hline Believed family at risk for diabetes & 1.0 & $6.5(4.9,8.4)$ & $20.2(13.8,29.6)$ \\
\hline \multicolumn{4}{|l|}{ Risk reducing behaviors } \\
\hline Collected information for family history & 1.0 & $1.3(1.1,1.6)$ & $1.8(1.5,2.2)$ \\
\hline Made lifestyle changes to prevent DM & 1.0 & $2.2(1.8,2.7)$ & $4.5(3.6,5.6)$ \\
\hline Tested in past 2 years & 1.0 & $1.6(1.3,1.9)$ & $2.4(2.0,3.0)$ \\
\hline Talked about diabetes with family & 1.0 & $3.1(2.6,3.7)$ & $6.5(5.2,8.2)$ \\
\hline Met recommended exercise guidelines & 1.0 & $1.0(0.9,1.2)$ & $1.4(1.1,1.7)$ \\
\hline
\end{tabular}

${ }^{a}$ Adjusted for demographic characteristics age, sex, race, education, and obesity.

Table 5

Sensitivity, specificity, and positive and negative predictive value of family history of diabetes compared to obesity

\begin{tabular}{|c|c|c|c|c|c|c|c|c|}
\hline Risk factor & $\begin{array}{l}\text { Diabetes } \\
(\mathrm{N})\end{array}$ & $\begin{array}{l}\text { No diabetes } \\
(\mathrm{N})\end{array}$ & Total & $\begin{array}{c}\text { Diabetes prevalence } \\
(\%)\end{array}$ & $\begin{array}{l}\text { Sensitivity } \\
(\%)\end{array}$ & $\begin{array}{l}\text { Specificity } \\
(\%)\end{array}$ & $\begin{array}{l}\text { Positive predictive value } \\
(\%)\end{array}$ & $\begin{array}{c}\text { Negative predictive value } \\
(\%)\end{array}$ \\
\hline Increased family history & 196 & 989 & 1185 & 16.5 & 72.8 & 68.4 & 21.5 & 95.5 \\
\hline Obesity & 48 & 328 & 376 & 12.8 & 40.0 & 85.8 & 25.0 & 92.3 \\
\hline $\begin{array}{l}\text { Increased family history } \\
\text { and obesity }\end{array}$ & 133 & 214 & 347 & 38.3 & 29.4 & 94.4 & 38.3 & 91.8 \\
\hline Neither & 75 & 2278 & 2353 & 3.2 & 16.6 & 59.8 & 3.2 & 96.8 \\
\hline Total & 452 & 3809 & 4261 & - & - & - & - & - \\
\hline
\end{tabular}

disease, stratifying populations into different levels of familial risk can help identify populations with high prevalence of genetic risk factors in which the use of genetic testing (as they become available) will achieve the highest predictive power. ${ }^{28}$ Moreover, by examining public attitudes and knowledge regarding the importance of family history as a risk factor for disease, and assessing willingness to talk to and systematically collect information from relatives, this survey demonstrates a heightened public awareness of, and interest in familial risk of disease, undoubtedly influenced by the widespread media attention to the genetic basis of disease.

Until technological advances deliver on the expectations of population-based screening of genetic susceptibility to modifiable environmental risk factors, no single approach will be sufficient to combat the rising rates of diabetes and other common diseases related to lifestyle changes. Meanwhile, public health efforts to prevent or delay the onset of diabetes and to effectively minimize its sequelae through early detection and management efforts can be enhanced through creative use of existing and novel epidemiologic tools such as evaluation of family history to identify populations at increased risk for diabetes. ${ }^{22,23,29,30}$ Additionally, family history can help in the evaluation and comparison of other risk factors affecting groups with disparate risk levels of diabetes. Family history can be used not only to assess disease risk but also to examine the awareness of this risk and the motivation to engage in riskreducing behaviors.

\section{References}

1. Harris MI . Diabetes in America: epidemiology and scope of the problem. Diabetes Care 1998;21:C11-C14.

2. Harrison TA, Hindorff LA, Kim H, Wines RC, Bowen DJ, McGrath BB, Edwards KL. Family history of diabetes as a potential public health tool. Am J Prev Med 2003;24: 152-159.

3. O'Rahilly S, Barroso I, Wareham NJ. Genetic factors in type 2 diabetes: the end of the beginning? Science 2005;307:370-373.

4. Mensah GA, Mokdad AH, Ford E, Narayan KM, Giles WH, Vinicor F, Deedwania PC. Obesity, metabolic syndrome, and type 2 diabetes: emerging epidemics and their cardiovascular implications. Cardiol Clin 2004;22:485-504.

5. Newell AM. Genetics for targeting disease prevention: diabetes. Prim Care 2004;31: 743-66.

6. Arslanian SA, Bacha F, Saad R, Gungor N. Family history of type 2 diabetes is associated with decreased insulin sensitivity and an impaired balance between insulin sensitivity and insulin secretion in white youth. Diabetes Care 2005;28:115-119.

7. Arslanian SA. Type 2 diabetes mellitus in children: pathophysiology and risk factors. J Pediatr Endocrinol Metab 2000;13 Suppl 6:1385-1394.

8. Centers for Disease Control and Prevention: Prevalence of diabetes and impaired fasting glucose in adults-United States, 1999-2000. MMWR Morb Mortal Wkly Rep 2005;52:833-837.

9. Dabelea D, Pettitt DJ, Jones KL, Arslanian SA. Type 2 diabetes mellitus in minority children and adolescents. An emerging problem. Endocrinol Metab Clin North Am 1999;28:709-29.

10. Harris MI. Racial and ethnic differences in health care access and health outcomes for adults with type 2 diabetes. Diabetes Care 2001;24:454-459. 


\section{Hariri et al.}

11. Hydrie MZ, Basit A, Ahmedani MY, Badruddin N, Masood MQ, Miyan Z. Comparison of risk factors for diabetes in children of different socioeconomic status. J Coll Physicians Surg Pak 2005;15:74-77.

12. Libman I, Arslanian S. Type 2 diabetes in childhood: the American perspective. Horm Res 2003;59 Suppl 1:69-76.

13. Libman I, Arslanian SA. Type II diabetes mellitus: no longer just adults. Pediatr Ann 1999;28:589-593.

14. Kanaya AM, Narayan KM. Prevention of type 2 diabetes: data from recent trials. Prim Care 2003;30:511-526.

15. Narayan KM, Imperatore G, Benjamin SM, Engelgau MM. Targeting people with pre-diabetes. BMJ 2002;325:403-404.

16. Williamson DF, Vinicor F, Bowman BA. Primary prevention of type 2 diabetes mellitus by lifestyle intervention: implications for health policy. Ann Intern Med 2004;140:951-957.

17. Wing RR, Venditti E, Jakicic JM, Polley BA, Lang W. Lifestyle intervention in overweight individuals with a family history of diabetes. Diabetes Care 1998;21:350-359.

18. Wing RR. Behavioral treatment of obesity. Its application to type II diabetes. Dia betes Care 1993;16:193-199.

19. Annis AM, Caulder MS, Cook ML, Duquette D. Family history, diabetes, and other demographic and risk factors among participants of the National Health and Nutrition Examination Survey 1999-2002. Preventing Chronic Disease: Public Health Research, Practice, and Policy 2005;2:1-12.

20. Hunt SC, Gwinn M, Adams TD. Family history assessment: strategies for prevention of cardiovascular disease. Am J Prev Med 2003;24:136-142.
21. Kardia SL, Modell SM, Peyser PA. Family-centered approaches to understanding and preventing coronary heart disease. Am J Prev Med 2003;24:143-151.

22. Yoon PW, Scheuner MT, Peterson-Oehlke KL, Gwinn M, Faucett A, Khoury MJ Can family history be used as a tool for public health and preventive medicine? Genet Med 2002;4:304-310.

23. Yoon PW, Scheuner MT, Khoury MJ. Research priorities for evaluating family history in the prevention of common chronic diseases. Am J Prev Med 2003;24:128-135.

24. Bowen DJ, Ludman E, Press N, Vu T, Burke W. Achieving utility with family history: colorectal cancer risk. Am J Prev Med 2003;24:177-182.

25. Awareness of family health history as a risk factor for disease-United States, 2004 MMWR Morb Mortal Wkly Rep 2004;53:1044-1047.

26. Pollard WE. Use of consumer panel survey data for public health communication planning: an evaluation of survey results. American Statistical Association 2002 Proceedings of the Section on Health Policy Statistics 2002;2720-2724.

27. Scheuner MT, Wang SJ, Raffel LJ, Larabell SK, Rotter JI. Family history: a comprehensive genetic risk assessment method for the chronic conditions of adulthood. Am J Med Genet 1997;71:315-324.

28. Hedley AA, Ogden CL, Johnson CL, Carroll MD, Curtin LR, Flegal KM. Prevalence of overweight and obesity among US children, adolescents, and adults, 1999-2002. JAMA 2004;291:2847-2850.

29. Rich EC, Burke W, Heaton CJ, Haga S, Pinsky L, Short MP, Acheson L. Reconsidering the family history in primary care. J Gen Intern Med 2004;19:273-280.

30. Engelgau MM, Narayan KMV, Vinicor F. Identifying the target population primary prevention: the trade-offs. Diabetes Care 2002;25:2098-2099. 